\title{
The efficiency and efficacy of tranexamic acid in prevention of blood loss during or after caesarean delivery: a comparative study
}

\author{
Supriya Raina $^{1 *}$, V. Suguna ${ }^{1}$, Padmaja Prabraju ${ }^{2}$
}

\author{
${ }^{1}$ Department of Obstetrics and Gynecology, Mamata Academy of Medical Sciences, Bachupally, Hyderabad. \\ Telangana, India \\ ${ }^{2}$ Department of Obstetrics and Gynecology, Deccan College of Medical Sciences, Hyderabad, Telangana, India
}

Received: 11 February 2020

Accepted: 03 March 2020

*Correspondence:

Dr. Supriya Raina,

E-mail: rainasupriya34@gmail.com

Copyright: (C) the author(s), publisher and licensee Medip Academy. This is an open-access article distributed under the terms of the Creative Commons Attribution Non-Commercial License, which permits unrestricted non-commercial use, distribution, and reproduction in any medium, provided the original work is properly cited.

\begin{abstract}
Background: The practice of caesarean section is increasing day by day. Delivery by caesarean section can cause more complications than normal vaginal delivery and one of the most common complications is primary or secondary postpartum hemorrhage. The aim of present study was to study the efficacy and safety of tranexamic acid in reducing blood loss during and after caesarean section.

Methods: This study was conducted at Deccan College of Medical Sciences, Hyderabad. It was a prospective randomized double blind placebo controlled study. This study includes 60 pregnant women divided in to two groups. Just before the induction of anesthesia $1 \mathrm{gm}$ of tranexamic acid in $20 \mathrm{ml}$ of normal saline was given over 10 minutes in test group and $20 \mathrm{ml}$ of normal saline was infused in control group.

Results: The demographic characters of patients in two groups were comparable. There was no statistically significant difference in the heart rates, respiratory rates and blood pressures in the two groups. There was statistically significant difference in the quantity of the blood loss from during the operation and 2 hours postpartum $(p=0.003)$. Total mean blood loss in control group was $718.80 \pm 233.1 \mathrm{ml}$ and in study group was $554.28 \pm 207.8 \mathrm{ml}$. The drop in hemoglobin after caesarean section in study group was not significant where as in control group was significant. There was no significant difference in the prothrombin time and partial thromboplastin time in the groups, pre and post operatively. In this study the use of tranexamic acid reduced the dose of other uterotonics like syntocin in study group.

Conclusions: Tranexamic acid significantly reduced the amount of blood loss during the caesarean section and also reduced the use of other uterotonics. Thus, tranexamic acid can be used safely and effectively in subjects undergoing caesarean section.
\end{abstract}

Keywords: Blood loss, Caesarean section, Efficacy, Postpartum hemorrhage, Tranexamic acid

\section{INTRODUCTION}

The practice of caesarean section is increasing day by day. The rates of caesarean section (CS) have increased to as high as 25 to $30 \%$ in many areas of the world. Delivery by CS can cause more complications than normal vaginal delivery and one of the most common complications is primary or secondary postpartum haemorrhage (20\%). ${ }^{1}$ Postpartum haemorrhage (PPH) continues to be the main cause of maternal mortality in developing countries especially in Asia and Africa. Postpartum haemorrhage (PPH) is commonly defined as a blood loss of $500 \mathrm{ml}$ or more within 24 hours after birth, and affects about 5\% of all women giving birth around the world. Globally, nearly one quarter of all maternal deaths are associated with $\mathrm{PPH}$, and in most low-income countries it is the main cause of maternal mortality. ${ }^{2}$ Improving care during childbirth to prevent 
$\mathrm{PPH}$ is a necessary to reduce the global maternal mortality.

Many uterotonic agents such as oxytocin, methyl ergometrine were used in the past were ineffective to halt the bleeding or trauma as the potential causes of bleeding. To find low-cost and low-risk alternative methods of controlling obstetric haemorrhage many investigations on systemic anti-fibrinolytic agents were conducted, which were used in spinal, urologic, orthopaedics, and cardiac surgeries. Hence the one of the antifibrinolytic agent tranexamic acid (TXA) was also used for control of PPH.

Tranexamic acid is a synthetic lysine amino acid derivative, which diminishes the dissolution of haemostatic fibrin by plasmin. In the presence of tranexamic acid, the lysine receptor binding sites of plasmin for fibrin are occupied, preventing binding to fibrin monomers, thus preserving and stabilizing fibrin's matrix structure. The antifibrinolytic effects of tranexamic acid are mediated by reversible interactions at multiple binding sites within plasminogen. The high affinity lysine site of plasminogen is involved in its binding to fibrin. Saturation of the high affinity binding site with tranexamic acid displaces plasminogen from the surface of fibrin. Although plasmin may be formed by conformational changes in plasminogen it's binding to and dissolution of the fibrin matrix is inhibited.

The aim of present investigation is to study the efficiency, efficacy and safety of tranexamic acid in reducing blood loss during and after caesarean section.

\section{METHODS}

This study was conducted at Deccan College of Medical Sciences, Hyderabad. It was a prospective randomized double blind placebo controlled study. For selection of patient's simple random technique was used. This study was conducted on 60 primipara or multipara singleton pregnant women at 37-40 weeks of gestation and ASA (American Society of Anesthesiologists) class I and II and pregnant women had cesarean delivery under spinal anesthesia. Pregnant women with heart, liver, kidney and brain and having blood disorders were excluded from the study. Pregnant women having allergy to tranexamic acid, history of thromboembolic disorders, abnormal placentation, severe pre-eclampsia, multiple pregnancy, macrosomia, polyhydromnios and those requiring blood transfusion due to anemia were also excluded from the study. Informed consent was taken from the patients and clinical history and investigations were noted and patients were divided in to two groups. The control group received normal saline and test group received the drug tranexamic acid. In the operating room, $\mathrm{C}$ and $\mathrm{T}$ packages were offered to the patients in order to make a choice, which only the nurse responsible for preparing the drug was aware of the content. All drugs were administered by an anesthesiologist who was unaware of managing and evaluating the patients.

Vitals like heart rate and blood pressure were monitored and haemogram, prothrombin time, kidney function tests were carried out pre and post operatively. All the drapes, sponges, pads were weighed preoperatively and post operatively for measuring blood loss. Just before the induction of anesthesia $1 \mathrm{gm}$ of tranexamic acid in $20 \mathrm{ml}$ of normal saline was given over 10 minutes in test group and $20 \mathrm{ml}$ of normal saline was infused in control group.

Time from administration of injection tranexamic acid to the time of skin incision was noted. Two suction containers were used, one for the amniotic fluid and one for the blood. Blood loss was calculated by measuring the blood collected in the suction apparatus and by weighing pads, towels, and drapes.

Total blood loss $=$ weight of all the drapes, sponges, gauzes, pads after the surgery -weight of drapes, gauzes, sponges, pads before surgery plus volume of blood collected in the suction container. Pulse rate, blood pressure, urine output, uterine contractility; side effects were charted hourly for six hours post operatively. If excessive bleeding was assessed by the operating surgeon, additional uterotonics were given.

\section{RESULTS}

The study was conducted at Deccan College of Medical Sciences, Hyderabad. It includes 60 patients, grouped in to test group and control group. The demographic characters of patients were shown in Table 1 and there was no significant difference between two groups with respect to age, height, weight, gestational age and gravidity.

\section{Table 1: Demographic data.}

\begin{tabular}{|llll|}
\hline & Control & Study & p value \\
\hline Age $($ years $)$ & $26.63 \pm 4.72$ & $26.88 \pm 6.89$ & 0.89 \\
\hline Height $(\mathrm{cm})$ & $151.02 \pm 4.73$ & $149.56 \pm 4.63$ & 0.87 \\
\hline Weight $(\mathrm{kg})$ & $55.11 \pm 3.54$ & $54.52 \pm 3.54$ & 0.92 \\
\hline $\begin{array}{l}\text { Gestational } \\
\text { age (in weeks) }\end{array}$ & $38.32 \pm 0.80$ & $38.47 \pm 0.910$ & 0.63 \\
\hline Gravidity & $2.21 \pm 0.84$ & $2.18 \pm 0.72$ & 0.52 \\
\hline
\end{tabular}

In systolic BP, no significant difference was observed between the groups during and after the caesarean delivery (Table 2). Additionally, although there was a significant difference between diastolic BP during and after the caesarean delivery in each group, no such difference was found between the two groups in each time period. In addition, considering the HR changes after the surgeries as well as HR changes in individual periods before and after the operations there were no statistically significant changes between the groups. 
Table 2: Vitals monitoring in two groups.

\begin{tabular}{|c|c|c|c|c|c|c|c|c|c|}
\hline & \multicolumn{3}{|c|}{ Immediate after placental delivery } & \multicolumn{3}{|c|}{1 hour after placental delivery } & \multicolumn{3}{|c|}{2 hours after placental delivery } \\
\hline & Study & Control & $\begin{array}{l}p \\
\text { value }\end{array}$ & Study & Control & $\begin{array}{l}p \\
\text { value }\end{array}$ & Study & Control & $\begin{array}{l}\text { p } \\
\text { value }\end{array}$ \\
\hline $\begin{array}{l}\text { Heart rate } \\
\text { (beats/min) }\end{array}$ & $91.12 \pm 10.1$ & $92.40 \pm 9.3$ & 0.35 & $92.46 \pm 8.9$ & $86.82 \pm 12.23$ & 0.45 & $91.56 \pm 10.26$ & $96.1 \pm 9.06$ & 0.46 \\
\hline $\begin{array}{l}\text { Resp. rate } \\
\text { (breaths } \\
\text { /min) }\end{array}$ & $18.23 \pm 2.99$ & $20.48 \pm 2.89$ & 0.31 & $20.24 \pm 4.86$ & $23.46 \pm 4.54$ & 0.1 & $19.80 \pm 4.00$ & $20.12 \pm 5.24$ & 0.29 \\
\hline $\begin{array}{l}\text { Systolic BP } \\
\text { mean } \\
(\mathrm{mmHg})\end{array}$ & $119.02 \pm 11.89$ & $123.06 \pm 11.35$ & 0.73 & $131.76 \pm 11.04$ & $123.76 \pm 11.49$ & 0.41 & $120.48 \pm 12.02$ & $122.50 \pm 9.16$ & 0.59 \\
\hline $\begin{array}{l}\text { Diastolic } \\
\text { BP mean } \\
(\mathrm{mmHg})\end{array}$ & $80.04 \pm 10.58$ & $79.28 \pm 7.09$ & 0.64 & $82.23 \pm 7.09$ & $79.84 \pm 9.73$ & 0.82 & $80.16 \pm 10.12$ & $79.72 \pm 8.47$ & 0.78 \\
\hline
\end{tabular}

Table 3: Blood loss during caesarean section and after caesarean section.

\begin{tabular}{|l|lll|}
\hline Blood loss & Control & Study group & p value \\
\hline Mean blood collected during operation $(\mathrm{mL})$ & $650.62 \pm 54.2$ & $510.25 \pm 58.7$ & 0.02 \\
\hline Mean blood collected 2 h after operation $(\mathrm{mL})$ & $68.20 \pm 28.48$ & $44.30 \pm 27.75$ & 0.03 \\
\hline Mean blood collected during and 2 h after operation $(\mathrm{mL})$ & $718.80 \pm 233.1$ & $554.28 \pm 207.8$ & 0.003 \\
\hline
\end{tabular}

Table 4: Pre and post-operative haemoglobin concentration, prothrombin time and thromboplastin time.

\begin{tabular}{|lllllll|}
\hline & \multicolumn{2}{c}{ Pre-0perative } & \multicolumn{3}{l|}{ Post-operative } \\
\hline & Control & Study & p value & Control & Study & p value \\
\hline Mean haemoglobin & $11.5 \pm 1.65$ & $11.1 \pm 1.43$ & 0.55 & $9.9 \pm 1.32$ & $10.5 \pm 1.43$ & 0.04 \\
\hline Mean prothrombin time (s) & $12.07 \pm 0.86$ & $11.89 \pm 0.72$ & 0.85 & $11.99 \pm 0.67$ & $11.43 \pm 0.43$ & 0.75 \\
\hline Mean partial thromboplastin time (s) & $30.83 \pm 2.9$ & $31.90 \pm 4.01$ & 0.72 & $31.04 \pm 0.55$ & $31.74 \pm 0.54$ & 0.68 \\
\hline
\end{tabular}

There was statistically significant difference in the quantity of the blood loss from during the operation and 2 hours postpartum $(p=0.003)$. Total mean blood loss in control group was $718.80 \pm 233.1 \mathrm{ml}$ and in study group was $554.28 \pm 207.8 \mathrm{ml}$. there exists a difference of $164 \mathrm{ml}$ which was highly significant (Table 3 ).

Table 5: Use of additional uterotonic during caesarean section.

\begin{tabular}{|l|lc|}
\hline $\begin{array}{l}\text { Additional uterotonics } \\
\text { [syntocin (IU)] }\end{array}$ & $\begin{array}{l}\text { Control } \\
\text { No. of pregnant people }\end{array}$ \\
\hline & 10 & Study group \\
\hline$<15$ & 15 & 6 \\
\hline 20 & 5 & 0 \\
\hline 30 & & 24 \\
\hline
\end{tabular}

The drop in haemoglobin after caesarean section in study group was not significant where as in control group was significant (Table 4). There was no significant difference in the prothrombin time and partial thromboplastin time in both groups pre and post operatively.

In this study the use of tranexamic acid reduced the dose of other uterotonics like oxytocin/syntocinon in study group (Table 5). Tranexamic acid significantly reduced the amount of blood loss during the caesarean section. It was not associated with any side effects and complication like thrombosis. Thus, TXA can be used safely and effectively in subjects undergoing caesarean section.

\section{DISCUSSION}

Increased blood loss can have its adverse effects such as raised morbidity and mortality, increased hospital stay, increased intra-operative duration, increased need for reexploration which may be fatal at times, also excessive bleeding can hamper oxygen delivery and lead to multiple organ failure and death. It holds true in PPH also. To reduce the PPH, uterotonics were used, but most of them were ineffective in reducing $\mathrm{PPH}^{1}$

During placental delivery, fibrinogen and fibrin are rapidly degraded, whereas plasminogen activators and fibrin degradation products (FDP) increase due to activation of the fibrinolytic system. This activation can last up to 6-10 hours postpartum, causing more bleeding, which can be taken care of by anti-fibrinolytic agents. Tranexamic acid exerts its antifibrinolytic effect by blocking the lysine-binding locus of the plasminogen and plasmin molecules, thereby preventing the binding of plasminogen and plasmin to the fibrin substrate. TXA also inhibits the conversion of plasminogen to plasmin by the plasminogen activators. Therefore, the use of TXA appears to reduce the blood loss. ${ }^{2}$ 
TXA is a potent inhibitor of fibrinolysis was first reported by Okamoto in $1962 .^{3}$ Since then, TXA has been widely used to treat heavy menstrual bleeding and to reduce blood loss in elective surgery where it reduces blood transfusion by about one-third. ${ }^{4-6}$ It has been used for the treatment of various types of bleeding for many years e.g. menorrhagia, postoperatively or intraoperatively. ${ }^{7,8}$

This study was a double blind placebo controlled trial which showed that TXA significantly reduced bleeding during placental delivery and up to two hours postpartum in CS. This study shows significant decrease in the bleeding volume in TXA group as compared with the control group. Based on the results, a lower mean amount of blood loss was found in the TXA group (510.25 \pm 58.7$)$ compared to control one $(650.62 \pm 54.2 \mathrm{ml})$ in terms of intra-operative and postoperative blood loss $(44.30 \pm 27.75$ $\mathrm{ml}$ versus $68.20 \pm 28.48 \mathrm{ml})$.

A study on efficacy of prophylactic tranexamic acid in reducing blood loss during and after caesarean section was carried. The blood loss during caesarean section was less in the tranexamic acid group compared to the placebo group. Similarly blood loss measured 6 hours after caesarean section was less in the tranexamic acid group compared to placebo group. 20-40 min before the time of incision was the ideal time gap for administering the injection tranexamic acid for its optimum efficacy. Tranexamic acid group had lesser requirement of uterotonic when compared to placebo, but need for blood transfusion was similar in both the groups. Greater fall in the hemoglobin and haematocrit occurred in placebo group compared to tranexamic acid group. The results of our study were in accordance with this study. ${ }^{9}$

In this study no significant difference was found between the groups regarding the mean age, mean gestational age, and the prothrombin time and partial thromboplastin time. These results were in comparison with other study in Iran. In that study also no significant difference was found between the groups regarding the mean age, mean gestational age, the prothrombin time and partial thromboplastin time. The tranexamic acid lowers the blood loss respectively which means that a significant difference was observed between both groups in this respect. ${ }^{10}$

Likewise, Li et al found significantly less blood loss during the intra-operative and postoperative periods in patients receiving TXA compared to that of the placebo group. ${ }^{11}$

Another study done by Mayur G et al, at Baroda, Gujarat with 100 patients out of which 50 were cases and 50 were control also showed that the tranexamic acid significantly reduced the quantity of blood loss from the end of LSCS to 2 hours postpartum. ${ }^{12}$

In this study there was significant difference was noted between the groups regarding changes in hemoglobin $\mathrm{Hb}$ ) concentration. These studies were in accordance with another study that included 90 primipara patients undergoing LSCS. It also showed that tranexamic acid significantly reduced the blood loss from the end of LSCS to 2 hours postpartum in the tranexamic group Hemoglobin 24 hours after LSCS was significantly greater in tranexamic group than control group $(12.57 \pm 1.33$ in the tranexamic group and $11.74 \pm 1.14$ in the control group, $\mathrm{p}=0.002) .{ }^{13}$ No complications or side effects were reported in either group.

\section{CONCLUSION}

Tranexamic acid significantly reduced the amount of blood loss during the caesarean section. Its use also reduced the use of other uterotonics. Thus, tranexamic acid can be used safely and effectively in subjects undergoing caesarean section.

Funding: No funding sources

Conflict of interest: None declared

Ethical approval: The study was approved by the Institutional Ethics Committee

\section{REFERENCES}

1. Carroli G, Cuesta C, Abalos E, Gulmezoglu AM. Epidemiology of postpartum haemorrhage: a systematic review. Best Pract Res Clin Obstet Gynaecol. 2008;22:999-1012.

2. WHO recommendations: uterotonics for the prevention of postpartum haemorrhage. Available at: www.who.int $>$ reproductivehealth $>$ publications $>$ uter otinics-pph. Accessed on $1^{\text {st }}$ February 2020.

3. Roberts I. Tranexamic acid: a recipe for saving lives in traumatic bleeding. $\mathrm{J}$ Tehran Heart Cent. 2011;6:178.

4. Lukes AS, Kouides PA, Moore KA. Tranexamic acid: a novel oral formulation for the treatment of heavy menstrual bleeding. Womens Health. 2011;7:151-8.

5. Caglar GS, Tasci Y, Kayikcioglu F, Haberal A. Intravenous tranexamic acid use in myomectomy: a prospective randomized double-blind placebo controlled study. Eur J Obstet Gynecol Reprod Biol. 2008;137:227-31.

6. Mayur G, Purvi P, Ashoo G, Pankaj D. Efficacy of tranexamic acid in decreasing blood loss during and after caesarean section: a randomized case controlled prospective study. J Obstet Gynecol India. 2007;57:227-30.

7. Gungorduk K, Yildırım G, Asıcıoglu O, Gungorduk OC, Sudolmus S, Ark C. Efficacy of intravenous tranexamic acid in reducing blood loss after elective caesarean section: a prospective, randomized, double-blind, placebo-controlled study. Am J Perinatol. 2011;28:233-40.

8. Wong J, El Beheiry H, Rampersaud YR, Lewis S, Ahn H, De Silva Y, et al. Tranexamic acid reduces perioperative blood loss in adult patients having spinal fusion surgery. Anesth Anag. 2008;107:1479-86. 
9. Bhavana G, Abhishek MV, Mittal S. Efficacy of prophylactic tranexamic acid in reducing blood loss during and after caesarean section. Inter $\mathrm{J}$ Reprod Contracept Obstet Gynecol. 2016;5(6):2011-6.

10. Milani F, Haryalchi K, Sharami SH, Atrkarroshan Z, Farzadi S. Prophylactic effect of tranexamic acid on hemorrhage during and after the cesarean section. Internat J Women's Health Reprod Sci. 2019;7(1):74-8.

11. Li C, Gong Y, Dong L, Xie B, Dai Z. Is prophylactic tranexamic acid administration effective and safe for postpartum hemorrhage prevention?: A systematic review and meta-analysis. Medicine (Baltimore). 2017;96(1):e5653.

12. Mayur G, Purvi P, Ashoo G, Desai P. Clinical observation of blood loss reduced by tranexamic acid during and after caesarean section: a multi-center, randomized trial. Obstet Gynecol India. 2007;57(3):227-30.

13. Sekhavat L, Tabatabaii A, Dalili M, Farajkhoda T, Tafti AD. Efficacy of tranexamic acid in reducing blood loss after caesarean section, Matern Fetal Neonatal Med. 2009;22(1):9-5.

Cite this article as: Raina S, Suguna V, Prabraju P. The efficiency and efficacy of tranexamic acid in prevention of blood loss during or after caesarean delivery: a comparative study. Int J Reprod Contracept Obstet Gynecol 2020;9:1549-53. 